\title{
Management of Refractory Diabetic Macular Edema: A Review Article
}

\author{
Hamidreza Torabi ${ }^{{ }^{*}}$ \\ ${ }^{1}$ Health Management Research Center, Baqiyatallah University of Medical Sciences, Tehran, Iran
}

Corresponding Author: Hamidreza Torabi, MD, Assistant Professor of Ophthalmology, Health Management Research Center, Baqiyatallah University of Medical Sciences, Tehran, Iran. Tel: +98-21-81263617, Email: dr_hamidrezatorabi@yahoo.com

Received February 2, 2018; Accepted February 28, 2018; Online Published March 20, 2018

\begin{abstract}
Diabetic retinopathy (DR) is a major cause of visual impairment worldwide. Visual reduction in patients with DR is usually related to diabetic macular edema (DME). Today, the intravitreal injection of anti-vascular endothelial growth factors (VEGF) is replacing macular laser photocoagulation as the standard treatment for DME; however, in some patients, incomplete responses to the anti-VEGF injection, defined as refractory DME, may occur. Currently, the sequence of using one treatment option and the timing to switch from one agent to another is not fully understood, and the data from clinical trials on the appropriate approach to manage refractory DME is insufficient. In the current study, a review was conducted to evaluate therapeutic options for the management of refractory DME.

Keywords: Diabetes Mellitus, Macular Edema, Intravitreal Injection, Vascular Endothelial Growth Factor, Vitrectomy Citation: Torabi H. Management of refractory diabetic macular edema: a review article. Int J Med Rev. 2018;5(1):27-34. doi:10.29252/IJMR050105.
\end{abstract}

\section{Introduction}

Despite improvement in medical and surgical treatments, diabetic retinopathy (DR) remains one of the major causes of visual reduction in the world..$^{1-5}$ The visual reduction in patients with DR is usually related to diabetic macular edema (DME) and/or retinal neovascularization..$^{5-7}$ Laser photocoagulation as the gold standard of treatment can maintain or improve visual acuity; however, it may result in a reduction in the visual field, color vision, or in contrast sensitivity impairment. ${ }^{8-10}$

Metabolic changes and inflammatory reactions in diabetic patients can lead to the loss of endothelial tight junctions and result in blood-retinal barrier dysfunction. ${ }^{7,11}$ DME is affected by the expression of inflammatory mediators such as vascular growth factor (VEGF), transforming growth factor- $\beta$, tumor necrosis factor- $\alpha$, interleukins, and matrix metalloproteinases. ${ }^{11-13}$ Therefore, intravitreal injections of anti-VEGFs may be effective in the treatment of DME, but not all patients respond to this treatment modality. Also, due to multiple and frequent injections, the compliance with treatment is usually low with an elevated risk of ocular or systemic complications. ${ }^{14}$

Corticosteroids can inhibit VEGF formation, prostaglandins, and other inflammatory mediators. ${ }^{15,16}$ It has been shown that the intravitreal injection of corticosteroids can reduce macular edema secondary to various ocular diseases. ${ }^{17,18}$ In comparison to systemic administration, the intravitreal injection of corticosteroids can deliver the appropriate concentration of drug to the retina despite a reduction in systemic side effects. ${ }^{16}$

Many previous studies have demonstrated that antiVEGFs have significant effects on the treatment of DME with reductions in macular edema and gains in visual acuity. Today, anti-VEGF agents are replacing laser photocoagulation as the primary gold standard. ${ }^{19-23}$ In some patients, optimal DME control was not achieved using anti-VEGFs; this group of patients is defined as persistent or refractory DME. However, there is no general agreement on the definition of refractory DME in the literature. The prevalence of refractory DME is estimated to be around $50 \% .^{19}$

In this study, a review was conducted to evaluate therapeutic options in the management of refractory DME.

\section{Anti-VEGF Switching}

In the REEF study, Dhoot et al prospectively evaluated the efficacy of $0.5 \mathrm{mg}$ and $2 \mathrm{mg}$ intravitreal ranibizumab injections in the treatment of persistent DME. ${ }^{24}$ They defined persistent DME as a central subfield thickness (CST) of more than $300 \mu \mathrm{m}$ after at least 2 injections of $1.25 \mathrm{mg}$ bevacizumab. In total, 43 patients received 3 monthly intravitreal $0.5 \mathrm{mg}$ ranibizumab injections. After 3 months, cases with residual DME changed to 3 monthly intravitreal $2 \mathrm{mg}$ ranibizumab injections. Dhoot et al found that CST had decreased by 113 $\mu \mathrm{m}$ and $165 \mu \mathrm{m}$ at months 3 and 6 , respectively, and mean visual acuity had increased by 6.4 letters and 8.8 letters at months 3 and 6 , respectively. The authors concluded that

Copyright $(0) 2018$ The Author(s). This is an open-access article distributed under the terms of the Creative Commons Attribution License (http:// creativecommons.org/licenses/by/4.0), which permits unrestricted use, distribution, and reproduction in any medium, provided the original work is properly cited. 
the intravitreal injection of $0.5 \mathrm{mg}$ or $2 \mathrm{mg}$ ranibizumab can improve anatomic and visual outcomes in eyes with previous low response or no response to intravitreal bevacizumab. Moreover, increasing the ranibizumab dosage from $0.5 \mathrm{mg}$ to $2 \mathrm{mg}$ can lead to better results in some eyes.

In their retrospective multi-center study, Ehrlich et al evaluated the outcomes of intravitreal ranibizumab injections in eyes with refractory DME following an initial minimum of 3 intravitreal bevacizumab injections (DERB study) ${ }^{25}$ In total, 202 eyes from 162 patients were included and followed for at least 12 months. A mean of $8.8 \pm 4.9$ bevacizumab injections were administered before switching to ranibizumab, and a mean of $7.0 \pm 2.7$ ranibizumab injections were administered in the follow-up period after switching. The median CST decreased significantly from $436 \pm 162 \mu \mathrm{m}$ to $319 \pm 113 \mu \mathrm{m}$, and the median $\log$ MAR visual acuity increased significantly from $0.40 \pm 0.48$ to $0.38 \pm 0.40$. This study further showed that a higher CST prior to switching and a higher number of ranibizumab injections after switching were associated with acceptable results. Ultimately, they concluded that switching from bevacizumab to ranibizumab can result in anatomical improvement in many cases with refractory DME and lead to $\geq 2$ lines of visual improvement in $22 \%$ of cases. In another retrospective study, Ciulla et al treated 33 eyes with refractory DME following prior treatments (including macular laser, triamcinolone acetonide, bevacizumab or dexamethasone implant) with $0.3 \mathrm{mg}$ intravitreal ranibizumab. ${ }^{26}$ After 48 weeks of follow up and a mean of 6 intravitreal ranibizumab injections, the mean CST improved from $384 \mu \mathrm{m}$ to $335 \mu \mathrm{m}$, and the mean best corrected visual acuity (BCVA) improved from $20 / 110$ to $20 / 90$. The authors demonstrated that intravitreal ranibizumab can be effective in the treatment of refractory DME.

Katz et al retrospectively assessed the efficacy of switching to ranibizumab in patients with refractory DME. ${ }^{27}$ In their study, 40 eyes of 32 patients with refractory DME who were initially treated with intravitreal bevacizumab were included. They showed that the CST was significantly reduced, but the improvement in visual acuity was not statistically significant following the conversion from bevacizumab to ranibizumab.

In a prospective randomized study, Ehlers et al evaluated the efficacy of intravitreal ranibizumab in the treatment of refractory DME with prior treatment with intravitreal bevacizumab. ${ }^{28} \mathrm{~A}$ total of 27 patients were enrolled in their study and treated with 3 monthly intravitreal ranibizumab injections, after which they were randomized to a treat-andextend (TAE) regimen (12 eyes) or to monthly injections (15 eyes) over 12 months. In the TAE group, the treatment interval was extended by 2 weeks to a maximum of 12 weeks if the CST was $300 \mu \mathrm{m}$ or less or if complete intra- or subretinal fluid absorption occurred. The mean BCVA increased significantly by 5.3 letters, and the mean CST decreased significantly by $99.6 \mu \mathrm{m}$ at 12 months. At the final visit, $18.5 \%$ of cases had gained 3 lines or more of vision, and $3.7 \%$ of cases had lost 3 lines or more. In the TAE group, treated patients gained 8.4 letters and CST decreased by $120.2 \mu \mathrm{m}$, while in the monthly injection group, patients gained 2.7 letters and
CST decreased by $83.1 \mu \mathrm{m}$. The authors demonstrated that switching to ranibizumab in patients with refractory DME to bevacizumab may result in significant anatomic and visual improvement, although TAE and monthly injection protocols resulted in the same outcomes.

In the ROTATE trial, the efficacy of $0.3 \mathrm{mg}$ intravitreal ranibizumab in the treatment of 30 eyes with persistent DME after bevacizumab injection was evaluated. ${ }^{29}$ Patients were divided into a sustained group and pro re nata (PRN) group. At month 12, the mean BCVA improvement from baseline was 6.4 letters in the PRN group, 6.7 letters in the sustained group, and 6.5 letters overall. The mean reduction in the CST was $127 \mu \mathrm{m}$ and $92 \mu \mathrm{m}$ in the PRN group and sustained group, respectively, and $116 \mu \mathrm{m}$ overall. Finally, the authors concluded that intravitreal injection of $0.3 \mathrm{mg}$ ranibizumab can improve the anatomic and visual outcomes in patients with refractory DME after bevacizumab injection.

In a study by Lee et al, 62 eyes with persistent DME following at least 3 monthly intravitreal bevacizumab injections were treated with a single intravitreal ranibizumab injection and were followed-up for 1 month, ${ }^{30}$ after which, anatomic responses were monitored monthly, and intravitreal ranibizumab was injected on a PRN protocol for 3 months. The mean CST was reduced significantly from $422 \mu \mathrm{m}$ to 346 $\mu \mathrm{m}$, and the mean BCVA improved from 20/49 to 20/46, a statistically insignificant result. In 39 eyes (62.9\%), anatomic responses were achieved. After 3 months and following the mean of 2.6 intravitreal ranibizumab injections in the nonresponder eyes, the mean CST improved significantly (from $492 \mu \mathrm{m}$ to $317 \mu \mathrm{m}$ ), but the BCVA remained unchanged (from 20/52 to 20/48, $P=0.066$ ).

Ashraf et al evaluated the efficacy of early switching from bevacizumab to ranibizumab or aflibercept in a retrospective study. ${ }^{31}$ A total of 59 eyes from 45 patients were evaluated; of them, 17 eyes were switched to aflibercept and 42 eyes were switched to ranibizumab. Their results showed significant improvements in BCVA and CST occurring in both groups, although no statistically significant difference in BCVA or CST was observed in the 2 groups. In addition, they found that CST, number of injections, or BCVA before switching affected the response to switching. In a retrospective study, 21 eyes from 19 patients with refractory DME who received 6 (median number) intravitreal injections of bevacizumab or ranibizumab were switched to intravitreal aflibercept injections. ${ }^{32}$ After switching, the median number of intravitreal aflibercept injections was 3. The mean central foveal thickness (CFT) following the first injection decreased significantly from $453.52 \mu \mathrm{m}$ to $362.57 \mu \mathrm{m}$, and the mean CFT had decreased significantly to $324.17 \mu \mathrm{m}$ at the final follow-up visit (median 5 months). The mean logMAR visual acuity improved from 0.42 to 0.39 after the first injection and to 0.37 at the final visit $(P=0.04)$. The authors demonstrated that switching to aflibercept can improve anatomic and visual outcomes in patients with refractory DME.

Rahimy et al evaluated the efficacy of switching to aflibercept in patients with DME unresponsive to ranibizumab and/or bevacizumab. ${ }^{33}$ In their retrospective 
study, 40 eyes from 37 patients with at least 4 intravitreal ranibizumab or bevacizumab injections before switching and a minimum of 2 aflibercept injections after switching were evaluated. The mean logMAR visual acuity improved from 0.60 (prior to switching) to $0.55(P=012)$. The mean central macular thickness (CMT) decreased from $459.2 \mu \mathrm{m}$ (prior to switching) to $348.7 \mu \mathrm{m}(P<0.0001)$. The authors concluded that switching to aflibercept from bevacizumab or ranibizumab in patients with refractory DME may lead to significant improvement in anatomic outcomes, but the improvement in visual acuity was not statistically significant.

In their prospective study, Wood et al treated 14 eyes with refractory DME unresponsive to bevacizumab and/ or ranibizumab with an intravitreal injection of $2 \mathrm{mg}$ aflibercept. ${ }^{34}$ One month after the single aflibercept injection, anatomic improvement had occurred in $79 \%$ of eyes, and the CST had improved from $421 \mu \mathrm{m}$ to $325 \mu \mathrm{m}(P<0.0132)$; however, improvement in visual acuity was detected in $21 \%$ of eyes.

Chen et al prospectively evaluated the visual and anatomic outcomes of 72 eyes with DME refractory to bevacizumab or ranibizumab after switching to intravitreal aflibercept. ${ }^{35}$ Three monthly doses of aflibercept were injected intravitreally. With an increase in the CST or visual gain of less than 1 line at 1 month following the conversion to aflibercept compared with before switching, the eye was considered a non-responder to aflibercept. One month following the aflibercept injection, $58.3 \%$ of eyes (42 eyes) had responded to switching. The mean BCVA improved from 0.65 logMAR to $0.31 \log$ MAR $(P=0.0008)$, and the CST decreased from $438.5 \mu \mathrm{m}$ to 297.9 $\mu \mathrm{m}(P=0.0004)$ in responders.

Bahrami et al evaluated the efficacy of switching to aflibercept in 43 eyes from 43 patients with DME and with CMT $>300 \mu \mathrm{m}$ unresponsive to at least 4 intravitreal bevacizumab injections in the prior 6 months. ${ }^{36}$ Five monthly intravitreal aflibercept injections were administered as a loading dose, and then the treatment interval was extended to 8 weeks. The mean number of intravitreal injections before switching was 16.6 during a period of 26.9 months. At month 24 , the mean CMT had decreased significantly from $417 \mu \mathrm{m}$ to $380 \mu \mathrm{m}$, and the mean BCVA had improved significantly from 67.8 letters to 71.0 letters. The authors concluded that switching to aflibercept was effective in improving visual and anatomic outcomes in patients with DME unresponsive to bevacizumab.

In a retrospective study, 49 eyes from 34 patients with DME refractory to bevacizumab were treated with intravitreal aflibercept injection. ${ }^{37}$ All patients had at least 3 intravitreal bevacizumab injections before switching to aflibercept, and all patients were followed-up for at least 3 months after switching. The mean visual acuity improved from $0.55 \log$ MAR to 0.46 $\operatorname{logMAR}(P=0.038)$, and the mean CMT decreased from 437 $\mu \mathrm{m}$ to $349 \mu \mathrm{m}(P<0.001)$. In $24 \%$ of eyes (12 eyes), macular edema was absorbed after the conversion to aflibercept. The authors found that the improvement in visual acuity and CMT was superior in eyes with poorer initial visual acuity prior to conversion compared to eyes with initial visual acuity better than $0.4 \log$ MAR.

Demircan et al compared the outcomes in eyes with refractory DME who received intravitreal aflibercept following prior unresponsive intravitreal ranibizumab injections with eyes who continued with intravitreal ranibizumab injections. ${ }^{38}$ In this retrospective study, 43 eyes with a CMT $\geq 350 \mu \mathrm{m}$ who received at least 3 monthly intravitreal ranibizumab injections and were then treated with either ranibizumab or aflibercept with a PRN regimen were included. This study showed that the CMT decreased significantly from baseline in both groups with switching to aflibercept or continued with ranibizumab. The mean changes in the CMT were $188.6 \mu \mathrm{m}$ in the switching group and $60.3 \mu \mathrm{m}$ in the continued ranibizumab group $(P=0.003)$. The results showed that, despite the anatomical benefits of switching to aflibercept, there were no visual benefits.

\section{Corticosteroids}

Corticosteroids reduce the production and release of VEGF, suppress pro-inflammatory cytokines and prostaglandins, reduce leukocytes migration, suppress the release of ICAM1 , enhance the barrier function of vascular endothelial cell tight junctions, and probably have a neuroprotective effect on the retina. ${ }^{39-44}$ Because of the known side-effects of corticosteroids, including glaucoma and cataract progression, they are not used as a first-line option in the management of DME. Usually, they are considered as the second-line modality, especially in DME refractory to anti-VEGF agents. ${ }^{45}$ Corticosteroids that are used for DME management include triamcinolone acetonide, fluocinolone acetonide insert, and dexamethasone implant.

Kim et al evaluated the efficacy of posterior sub-tenon triamcinolone acetonide injection in the treatment of DME unresponsive to bevacizumab. ${ }^{46}$ A total of 40 eyes from 34 patients with DME and CST $>300 \mu \mathrm{m}$ who experienced an increase in the CST following 1 or 2 intravitreal bevacizumab injections or no decrease following 3 or more intravitreal injections were enrolled in this retrospective study. Posterior sub-tenon injections of $20 \mathrm{mg}$ triamcinolone acetonide were administered. At month 6, the mean CST decreased from 476 $\mu \mathrm{m}$ to $427 \mu \mathrm{m}(P<0.001)$, and the mean BCVA improved from 0.56 to $0.48 \log$ MAR $(P=0.133)$. The mean intraocular pressure was $15.50 \mathrm{~mm} \mathrm{Hg}$ at baseline and $15.56 \mathrm{~mm} \mathrm{Hg}$ at month 6.

Shoeibi et al reported the results of adding $2 \mathrm{mg}$ triamcinolone acetonide to intravitreal bevacizumab for the treatment of refractory DME. ${ }^{47}$ They defined refractory DME as persistent macular edema after laser photocoagulation. The authors randomized 115 eyes from 101 patients into 3 study groups: the intravitreal bevacizumab group (41 eyes) that received 3 intravitreal injections of $1.25 \mathrm{mg}$ bevacizumab at 6-week intervals, the combined intravitreal bevacizumab and triamcinolone acetonide group (37 eyes) that received $2 \mathrm{mg}$ of intravitreal triamcinolone acetonide combined with the first intravitreal bevacizumab injection, and the sham injection group. CMT was reduced significantly in the intravitreal bevacizumab group, but the reduction was not 
statistically significant in the combined bevacizumab and triamcinolone acetonide group. Also, visual improvement was not statistically significant in any of the groups. The authors concluded that intravitreal bevacizumab injections have beneficial effects for the management of refractory DME, but adding triamcinolone acetonide offers no additional benefits.

Azad et al enrolled 60 patients with refractory DME into their prospective study. ${ }^{48}$ They defined refractory DME as persistent DME with CMT $>250 \mu \mathrm{m}$ after at least 2 sessions of laser photocoagulation. Patients were randomized into 3 groups: group 1 included patients treated with 1.25 $\mathrm{mg}$ intravitreal bevacizumab, group 2 included patients treated with $4 \mathrm{mg}$ intravitreal triamcinolone acetonide, and group 3 included patients who underwent macular laser photocoagulation. At month 6, the BCVA had improved significantly from 20/160 to 20/80 in group 1 and from 20/125 to $20 / 63$ in group 2. The CMT reduction from baseline was statistically significant in both groups 1 and 2. The BCVA improvement (from 20/100 to 20/80) was not statistically significant in group 3. At the 6-month follow-up, the mean CMT had increased from $358 \mu \mathrm{m}$ to $398 \mu \mathrm{m}$ in the eyes in group 3. Four eyes in group 1 and 10 eyes in group 2 showed cataract progression, and 6 eyes in group 2 required cataract extraction. Moreover, 10 eyes in group 2 showed intraocular pressure elevation from baseline; however, no eyes required surgical treatment. Ultimately, this study showed that both intravitreal bevacizumab and intravitreal triamcinolone acetonide may be effective in the management of refractory DME; however, intravitreal triamcinolone acetonide may lead to cataract progression or intraocular pressure elevation.

Chan et al evaluated the efficacy of triple therapy including $70 \mathrm{mg}$ sub-tenon triamcinolone acetonide, $1.25 \mathrm{mg}$ intravitreal bevacizumab, and macular laser photocoagulation for the treatment of refractory DME. ${ }^{49}$ They included 29 eyes of 29 patients to the triple therapy group and compared them with 18 eyes from 18 patients who were treated with macular laser photocoagulation alone. At month 12, CMT had decreased significantly from $441 \mu \mathrm{m}$ to $298 \mu \mathrm{m}$ in the triple therapy group, but changes in BCVA were not statistically significant. In the laser photocoagulation group, no significant changes in CMT or BCVA had occurred.

In September 2014, dexamethasone implant (Ozurdex) was approved by the USFDA for the management of DME. Unsal et al evaluated the efficacy of the Ozurdex implant in the treatment of refractory DME defined as CMT $\geq 300 \mu \mathrm{m}$ after at least 3 intravitreal bevacizumab or ranibizumab injections. ${ }^{50}$ They included 46 eyes from 46 patients in this retrospective study and found that BCVA improved significantly in the first 4 months after the Ozurdex implantation; however, no significant changes were detected after 4 months. Moreover, CMT decreased significantly after 3 months, but no statistically significant changes were observed after 3 months. The authors concluded that the Ozurdex implant may be effective in the treatment of refractory DME; however, anatomical and visual improvement occurred in the first 3 months following treatment, and frequent injections may be required.

Pacella et al reported the long-term results of Ozurdex implantation in patients with refractory DME. ${ }^{51}$ A $700-\mu \mathrm{g}$ Ozurdex was implanted in 32 patients; the results showed that visual acuity increased significantly at $1,3,4,9$, and 15 months after treatment, but at 6,12, and 18 months, visual acuity tended to return to initial values. The authors concluded that the intravitreal dexamethasone implant can improve the CMT and BCVA in patients with refractory DME. In another prospective study, the efficacy of the 700- $\mu$ g Ozurdex implant in the treatment of refractory DME was evaluated..$^{52}$ In total, 40 eyes with refractory DME and 36 eyes with treatmentnaïve DME were included. After treatment with the Ozurdex implant, BCVA improved significantly in both refractory and treatment-naïve groups; however, the improvement in BCVA was significantly better in the treatment-naive eyes. The reduction in CMT was significant and similar in both groups.

In their retrospective study, Iglicki et al evaluated the efficacy of Ozurdex implant in the treatment of refractory DME and compared it with treatment-naïve DME cases. ${ }^{53}$ After 24 months, BCVA had improved significantly in both groups, while vision gain was significantly better in the treatmentnaïve eyes. At 24 months, CST was reduced significantly in both groups.

Maturi et al evaluated 40 eyes with refractory DME and BCVA between 20/32 and 20/320 and CST>20 $\mu \mathrm{m} .{ }^{54}$ The patients were randomized to receive a combination of bevacizumab plus Ozurdex implant or to receive bevacizumab alone. In the combination therapy group, an intravitreal bevacizumab injection was administered at baseline and Ozurdex was implanted at months 1, 5, and 9; in the bevacizumab monotherapy group, intravitreal bevacizumab was injected if needed (PRN). The mean BCVA changes at month 12 were similar in both groups $(P=0.75)$; however, the mean reduction in CST was significantly greater in the combination therapy group $(P=0.03)$. In addition, in the combination therapy group, 3 fewer bevacizumab injections were administered.

In another study, Maturi et al evaluated 129 eyes from 116 patients with refractory DME who had previously received at least 3 intravitreal anti-VEGF injections. ${ }^{55}$ The patients were randomized to receive the 700- $\mu$ g Ozurdex implant (65 eyes: combination therapy group) or sham injections (64 eyes: ranibizumab group) in addition to $0.3 \mathrm{mg}$ intravitreal ranibizumab injections every 4 weeks in both treatment groups. At 24 weeks, the mean BCVA improvement was similar in both treatment groups $(P=0.73)$, and the mean reduction in CST was significantly greater in the combination therapy group $(P<0.001)$. In the combination therapy group, intraocular pressure elevation occurred in $29 \%$ of eyes. The authors concluded that the addition of an intravitreal Ozurdex implant to the intravitreal ranibizumab injection does not improve visual acuity more than ranibizumab monotherapy in patients with refractory DME.

In a recent retrospective, multicenter study, Busch et al compared the outcomes of continued anti-VEGF therapy with Ozurdex implant in eyes with refractory DME. ${ }^{56}$ Patients who had a visual gain of $\leq 5$ letters or $\leq 20 \%$ CST reduction after 3 monthly intravitreal anti-VEGF injections were included 
and randomized to receive continued anti-VEGF therapy or an Ozurdex implant. Totally, 110 eyes from 105 patients were enrolled in this study. At 12 months, the mean improvement in visual acuity and the mean reduction in CST were significantly greater in the Ozurdex implant group $(P=0.004$ and $P=0.024$, respectively). In addition, this study showed that a visual gain $\geq 10$ letters was more likely to happen in the Ozurdex implant group $(P=0.24)$.

Fluocinolone acetonide intravitreal implant (Iluvien) is another sustained-release intravitreal steroid that has been evaluated for the treatment of refractory DME. The Iluvien implant contains $190 \mu \mathrm{g}$ of fluocinolone acetonide and releases $0.2 \mu \mathrm{g}$ a day up to 36 months. ${ }^{57}$ In a retrospective study, 15 eyes from 10 patients with refractory DME following either intravitreal anti-VEGF injection and/or intravitreal steroid injection (triamcinolone acetonide or Ozurdex implant) were included and treated with Iluvien implants. ${ }^{58}$ Compared to baseline, BCVA improved in 11 eyes (73.3\%), remained unchanged in 2 eyes (13.3\%), and decreased in 2 eyes (13.3\%). Intraocular pressure elevation occurred in 2 eyes, one of which required cyclocryotherapy. Ultimately, the authors concluded that intravitreal Iluvien implant was an effective therapeutic option for patients with refractory DME.

In their prospective study, Massin et al evaluated the efficacy of Iluvien implant in refractory DME cases with inadequate responses to laser therapy (group 1) or laser and anti-VEGF therapy (group 2). ${ }^{59} \mathrm{~A}$ total of 16 eyes were included and treated with intravitreal Iluvien implant. At month 12 after Iluvien implantation, the mean visual gain and the mean CMT reduction were 5.6 letters and $299 \mu \mathrm{m}$ in group 1 and 0.9 letters and $251 \mu \mathrm{m}$ in group 2, respectively.

Elaraoud et al treated 22 eyes with refractory DME using intravitreal Iluvien implant. ${ }^{60}$ After 3 months, the mean reduction in CMT and the mean visual acuity gain were 148 $\mu \mathrm{m}$ and 6.4 letters, respectively. Overall, in 18 eyes (68.2\%), CMT was improved, and 15 of them also had improved visual acuity. No reduction in CMT was seen in 4 of the 22 included eyes. In another study, Elaraoud et al reported the 6 months and 12 months results of bilateral Iluvien implantation for bilateral refractory DME. ${ }^{61}$ At the final visit, visual acuity had improved in 9 of the 10 included eyes. The mean CMT had reduced significantly from $645.3 \mu \mathrm{m}$ to $287.4 \mu \mathrm{m}$, and the mean visual acuity had improved significantly from 44.5 letters to 55 letters. This study demonstrated that bilateral Iluvien implantation may be effective in the treatment of eyes with bilateral refractory DME.

Because of the increased clearance of a single injection of intravitreal anti-VEGF in vitrectomized eyes, anti-VEGFs may be less effective in the treatment of DME in vitrectomized eyes; slow-release agents such as the Ozurdex implant or Iluvien implant may be more effective. ${ }^{62-64}$ Kumar et al treated 2 vitrectomized eyes with refractory DME using Iluvien implants and showed that DME was completely resolved up to 1 year. ${ }^{65}$ In a retrospective study, the efficacy of intravitreal implants for refractory DME in vitrectomized and nonvitrectomized eyes was compared. ${ }^{66}$ In total, 24 vitrectomized eyes (group 1) and 19 non-vitrectomized eyes (group 2) were enrolled in this study, treated with Iluvien implants, and followed-up for a mean of 8.5 months. At the final visit, the mean improvement in BCVA was 16.9 and 8.2 letters in group 1 and group 2, respectively. A gain of 15 letters or more occurred in $37.5 \%$ of eyes in group 1 and $36.8 \%$ of eyes in group 2. The mean reduction in CST was $217.7 \mu \mathrm{m}$ in group 1 and $155.6 \mu \mathrm{m}$ in group 2. At the final visit, there were no significant differences between the eyes in group 1 and group 2 regarding BCVA and CST changes.

\section{Surgery}

Pars plana vitrectomy (PPV) with or without internal limiting membrane (ILM) peeling has been used for the treatment of refractory DME. In a prospective study, 28 eyes with refractory DME to previous anti-VEGF therapy and with CMT $\geq 300$ $\mu \mathrm{m}$ were treated with 23-gauge PPV and ILM peeling, ${ }^{67}$ after which, 0.3 to $0.5 \mathrm{ml}$ of balanced salt solution (BSS) was injected into the sub-retinal space using a 38-gauge cannula to detach the fovea. The mean CMT decreased from $496 \mu \mathrm{m}$ to $274 \mu \mathrm{m}$, and the mean BCVA in decimal form improved significantly from 0.2 to 0.4 . The author concluded that PPV with ILM peeling and with the foveal detachment technique can be effective in the management of refractory DME cases.

Ghassemi et al evaluated the effectiveness of PPV with membranectomy and ILM peeling in the treatment of eyes with refractory DME and non-tractional epiretinal membrane. ${ }^{68}$ All patients were treated before surgery with at least 2 intravitreal bevacizumab injections and 1 intravitreal triamcinolone acetonide injection. In all, 12 eyes from 11 patients were evaluated and followed-up for a mean period of 14.5 months. The mean CMT decreased significantly from $559 \mu \mathrm{m}$ to $354 \mu \mathrm{m}(P=0.001)$; however, the improvement in BCVA was not statistically significant (from 0.84 to 0.72 $\log$ MAR, $P=0.967)$. This study showed that despite the reduction in CMT, PPV with membranectomy and ILM peeling cannot significantly improve the BCVA in eyes with refractory DME and non-tractional epiretinal membrane.

\section{Conclusions}

Previous studies have shown that the chronicity of macular edema leads to poor visual outcomes. Thus, in cases with incomplete response to one therapeutic option, a change in therapeutic modality should be considered soon to achieve macular edema resolution and better final visual results. Today, the sequence of using one treatment option and the timing to switch from one agent to another is not fully understood, and the data from clinical trials regarding the appropriate approach to the management of refractory DME is insufficient. Adequate patient education and systemic control of hyperglycemia, hyperlipidemia, and hypertension are valuable in the management of refractory DSME. ${ }^{69}$

In cases with refractory DME following intravitreal bevacizumab or ranibizumab injection, switching to aflibercept may result in favorable outcomes in some cases; however, if adequate responses were not achieved after 3 intravitreal aflibercept injections, intravitreal Ozurdex implant may be a practical choice, especially in patients with severe DME and 
in pseudophakic eyes. Intravitreal anti-VEGFs can be used to supplement the effects of intravitreal Ozurdex implantation, and at the end of the Ozurdex's life (3-4 months), a repeat implant may be used. The treatment of focal leaks using macular laser photocoagulation based on fluorescein angiography may be an effective adjuvant option. Intravitreal Iluvien implantation can be used as an alternative modality with a longer duration of action compared with Ozurdex. In cases of intravitreal corticosteroid usage, the intraocular pressure should be monitored regularly. PPV may be used early in eyes with vitreomacular traction or after resistance to other treatment modalities in eyes without traction; however, PPV may result in an anatomical improvement without significant visual improvement. Ultimately, DME may persist in some cases despite full treatment. Further studies are required to achieve alternative options in persistent DME eyes.

\section{Conflict of Interest Disclosures}

The author declares that he has no conflicts of interest.

\section{References}

1. Zhang $X$, Saaddine JB, Chou CF, et al. Prevalence of diabetic retinopathy in the United States, 2005-2008. JAMA. 2010;304(6):649-656. doi:10.1001/jama.2010.1111.

2. Ting DS, Cheung GC, Wong TY. Diabetic retinopathy: global prevalence, major risk factors, screening practices and public health challenges: a review. Clin Exp Ophthalmol. 2016;44(4):260277. doi:10.1111/ceo.12696.

3. Sivaprasad S, Gupta B, Crosby-Nwaobi R, Evans J. Prevalence of diabetic retinopathy in various ethnic groups: a worldwide perspective. Surv Ophthalmol. 2012;57(4):347-370. doi:10.1016/j. survophthal.2012.01.004.

4. Liu L, Wu X, Liu L, et al. Prevalence of diabetic retinopathy in mainland China: a meta-analysis. PLoS One. 2012;7(9):e45264. doi:10.1371/journal.pone.0045264.

5. Cheung N, Mitchell P, Wong TY. Diabetic retinopathy. Lancet. 2010;376(9735):124-136. doi:10.1016/s0140-6736(09)62124-3.

6. Hayreh SS. Neovascular glaucoma. Prog Retin Eye Res. 2007;26(5):470-485. doi:10.1016/j.preteyeres.2007.06.001.

7. Das A, McGuire PG, Rangasamy S. Diabetic macular edema: pathophysiology and novel therapeutic targets. ophthalmology. 2015;122(7):1375-1394. doi:10.1016/j.ophtha.2015.03.024.

8. Bhagat N, Grigorian RA, Tutela A, Zarbin MA. Diabetic macular edema: pathogenesis and treatment. Surv Ophthalmol. 2009;54(1):1-32. doi:10.1016/j.survophthal.2008.10.001.

9. Schatz $H$, Madeira D, McDonald HR, Johnson RN. Progressive enlargement of laser scars following grid laser photocoagulation for diffuse diabetic macular edema. Arch Ophthalmol. 1991;109(11):1549-1551. doi:10.1001/ archopht.1991.01080110085041.

10. Laursen ML, Moeller F, Sander B, Sjoelie AK. Subthreshold micropulse diode laser treatment in diabetic macular oedema. $\mathrm{Br} J$ Ophthalmol. 2004;88(9):1173-1179. doi:10.1136/ bjo.2003.040949.

11. Tang J, Kern TS. Inflammation in diabetic retinopathy. Prog Retin Eye Res.2011;30(5):343-358.doi:10.1016/j.preteyeres.2011.05.002.

12. Aveleira CA, Lin CM, Abcouwer SF, Ambrosio AF, Antonetti DA. TNF-alpha signals through PKCzeta/NF-kappaB to alter the tight junction complex and increase retinal endothelial cell permeability. Diabetes. 2010;59(11):2872-2882. doi:10.2337/ db09-1606.

13. Behzadian MA, Wang XL, Windsor LJ, Ghaly N, Caldwell RB. TGFbeta increases retinal endothelial cell permeability by increasing MMP-9: possible role of glial cells in endothelial barrier function. Invest Ophthalmol Vis Sci. 2001;42(3):853-859.
14. Brown DM, Nguyen QD, Marcus DM, et al. Long-term outcomes of ranibizumab therapy for diabetic macular edema: the 36-month results from two phase III trials: RISE and RIDE. Ophthalmology. 2013;120(10):2013-2022. doi:10.1016/j.ophtha.2013.02.034.

15. Wang K, Wang Y, Gao L, Li X, Li M, Guo J. Dexamethasone inhibits leukocyte accumulation and vascular permeability in retina of streptozotocin-induced diabetic rats via reducing vascular endothelial growth factor and intercellular adhesion molecule-1 expression. Biol Pharm Bull. 2008;31(8):1541-1546. doi:10.1248/ bpb.31.1541.

16. Tamura H, Miyamoto K, Kiryu J, et al. Intravitreal injection of corticosteroid attenuates leukostasis and vascular leakage in experimental diabetic retina. Invest Ophthalmol Vis Sci. 2005;46(4):1440-1444. doi:10.1167/iovs.04-0905.

17. Haller JA, Dugel P, Weinberg DV, Chou C, Whitcup SM. Evaluation of the safety and performance of an applicator for a novel intravitreal dexamethasone drug delivery system for the treatment of macular edema. Retina. 2009;29(1):46-51. doi:10.1097/ IAE.0b013e318188c814.

18. Pacella F, Smaldone G, Albanese G, Campagna O, Turchetti P, Pacella E. Treatment chronic macular edema in Vogt-Koyanagi Harada syndrome with dexamethasone intravitreal implant: description of three case. Senses and Sciences. 2015;2(1):57-63. doi:10.14616/sands.

19. Elman MJ, Bressler NM, Qin H, et al. Expanded 2-year followup of ranibizumab plus prompt or deferred laser or triamcinolone plus prompt laser for diabetic macular edema. Ophthalmology. 2011;118(4):609-614. doi:10.1016/j.ophtha.2010.12.033.

20. Do DV, Nguyen QD, Boyer D, et al. One-year outcomes of the da Vinci Study of VEGF Trap-Eye in eyes with diabetic macular edema. Ophthalmology. 2012;119(8):1658-1665. doi:10.1016/j. ophtha.2012.02.010.

21. Elman MJ, Aiello LP, Beck RW, et al. Randomized trial evaluating ranibizumab plus prompt or deferred laser or triamcinolone plus prompt laser for diabetic macular edema. Ophthalmology. 2010;117(6):1064-1077.e1035. doi:10.1016/j. ophtha.2010.02.031.

22. Nguyen QD, Brown DM, Marcus DM, et al. Ranibizumab for diabetic macular edema: results from 2 phase III randomized trials: RISE and RIDE. Ophthalmology. 2012;119(4):789-801. doi:10.1016/j.ophtha.2011.12.039.

23. Wells JA, Glassman AR, Ayala AR, et al. Aflibercept, bevacizumab, or ranibizumab for diabetic macular edema. N Engl J Med. 2015;372(13):1193-1203. doi:10.1056/NEJMoa1414264.

24. Dhoot DS, Pieramici DJ, Nasir M, et al. Residual edema evaluation with ranibizumab $0.5 \mathrm{mg}$ and $2.0 \mathrm{mg}$ formulations for diabetic macular edema (REEF study). Eye (Lond). 2015;29(4):534-541. doi:10.1038/eye.2014.338.

25. Ehrlich R, Dan I, Deitch I, Axer-Siegel R, Mimouni K. The effectiveness of intravitreal ranibizumab in patients with diabetic macular edema who have failed to respond to intravitreal bevacizumab. Ophthalmologica. 2016;235(3):133-136. doi:10.1159/000444103.

26. Ciulla TA, Hussain RM, Ciulla LM, Sink B, Harris A. Ranibizumab for diabetic macular edema refractory to multiple prior treatments. Retina. 2016;36(7):1292-1297. doi:10.1097/ iae.0000000000000876.

27. Katz G, Moisseiev E, Goldenberg D, et al. Ranibizumab for persistent diabetic macular edema after bevacizumab treatment. Eur J Ophthalmol. 2017;27(2):210-214. doi:10.5301/ejo.5000838.

28. Ehlers JP, Wang K, Singh RP, et al. A prospective randomized comparative dosing trial of ranibizumab in bevacizumab-resistant diabetic macular edema: the REACT Study. Ophthalmol Retina. 2018;2(3):217-224. doi:10.1016/j.oret.2017.07.004.

29. Fechter C, Frazier H, Marcus WB, Farooq A, Singh H, Marcus DM. Ranibizumab $0.3 \mathrm{mg}$ for persistent diabetic macular edema after recent, frequent, and chronic bevacizumab: the ROTATE Trial. Ophthalmic Surg Lasers Imaging Retina. 2016;47(11):1-18. 
doi:10.3928/23258160-20161031-07.

30. Lee JH, Lee WK, Kim SE. Short-term outcomes of switching to ranibizumab therapy for diabetic macular edema in patients with persistent fluid after bevacizumab therapy. J Ocul Pharmacol Ther. 2016;32(10):659-664. doi:10.1089/jop.2016.0074.

31. Ashraf M, Souka AA, ElKayal H. Short-term effects of early switching to ranibizumab or aflibercept in diabetic macular edema cases with non-response to bevacizumab. Ophthalmic Surg Lasers Imaging Retina. 2017;48(3):230-236. doi:10.3928/2325816020170301-06.

32. Lim LS, Ng WY, Mathur R, et al. Conversion to aflibercept for diabetic macular edema unresponsive to ranibizumab or bevacizumab. Clin Ophthalmol. 2015;9:1715-1718. doi:10.2147/ opth.s81523.

33. Rahimy E, Shahlaee A, Khan MA, et al. Conversion to aflibercept after prior anti-VEGF therapy for persistent diabetic macular edema. Am J Ophthalmol. 2016;164:118-127.e112. doi:10.1016/j. ajo.2015.12.030.

34. Wood EH, Karth PA, Moshfeghi DM, Leng T. Short-term outcomes of aflibercept therapy for diabetic macular edema in patients with incomplete response to ranibizumab and/or bevacizumab. Ophthalmic Surg Lasers Imaging Retina. 2015;46(9):950-954. doi:10.3928/23258160-20151008-08.

35. Chen YY, Chang PY, Wang JK. Intravitreal aflibercept for patients with diabetic macular edema refractory to bevacizumab or ranibizumab: analysis of response to aflibercept. Asia Pac J Ophthalmol (Phila). 2017;6(3):250-255. doi:10.22608/ apo.2016186.

36. Bahrami B, Hong T, Zhu M, Schlub TE, Chang A. Switching therapy from bevacizumab to aflibercept for the management of persistent diabetic macular edema. Graefes Arch Clin Exp Ophthalmol. 2017;255(6):1133-1140. doi:10.1007/s00417-017-3624-y.

37. Laiginhas $\mathrm{R}$, Silva $\mathrm{MI}$, Rosas $\mathrm{V}$, et al. Aflibercept in diabetic macular edema refractory to previous bevacizumab: outcomes and predictors of success. Graefes Arch Clin Exp Ophthalmol. 2018;256(1):83-89. doi:10.1007/s00417-017-3836-1.

38. Demircan A, Alkin Z, Yesilkaya C, Demir G, Kemer B. Comparison of intravitreal aflibercept and ranibizumab following initial treatment with ranibizumab in persistent diabetic macular edema. J Ophthalmol. 2018;2018:4171628. doi:10.1155/2018/4171628.

39. Miyamoto K, Khosrof S, Bursell SE, et al. Prevention of leukostasis and vascular leakage in streptozotocin-induced diabetic retinopathy via intercellular adhesion molecule- 1 inhibition. Proc Natl Acad Sci U S A. 1999;96(19):10836-10841. doi:10.1073/ pnas.96.19.10836.

40. Sohn HJ, Han DH, Kim IT, et al. Changes in aqueous concentrations of various cytokines after intravitreal triamcinolone versus bevacizumab for diabetic macular edema. Am J Ophthalmol. 2011;152(4):686-694. doi:10.1016/j.ajo.2011.03.033.

41. Felinski EA, Antonetti DA. Glucocorticoid regulation of endothelial cell tight junction gene expression: novel treatments for diabetic retinopathy. Curr Eye Res. 2005;30(11):949-957. doi:10.1080/02713680500263598.

42. Wilson CA, Berkowitz BA, Sato $Y$, Ando N, Handa JT, de Juan E Jr. Treatment with intravitreal steroid reduces bloodretinal barrier breakdown due to retinal photocoagulation. Arch Ophthalmol. 1992;110(8):1155-1159. doi:10.1001/ archopht.1992.01080200135041.

43. Bhisitkul RB, Winn BJ, Lee OT, et al. Neuroprotective effect of intravitreal triamcinolone acetonide against photoreceptor apoptosis in a rabbit model of subretinal hemorrhage. Invest Ophthalmol Vis Sci. 2008;49(9):4071-4077. doi:10.1167/iovs.081892.

44. Glybina IV, Kennedy A, Ashton P, Abrams GW, lezzi R. Intravitreous delivery of the corticosteroid fluocinolone acetonide attenuates retinal degeneration in S334ter-4 rats. Invest Ophthalmol Vis Sci. 2010;51(8):4243-4252. doi:10.1167/iovs.09-4492.

45. Grover D, Li TJ, Chong CC. Intravitreal steroids for macular edema in diabetes. Cochrane Database Syst Rev. 2008(1):Cd005656. doi:10.1002/14651858.CD005656.pub2.

46. Kim MW, Moon H, Yang SJ, Joe SG. Effect of posterior subtenon triamcinolone acetonide injection on diabetic macular edema refractory to intravitreal bevacizumab injection. Korean J Ophthalmol. 2016;30(1):25-31. doi:10.3341/kjo.2016.30.1.25.

47. Shoeibi N, Ahmadieh H, Entezari M, Yaseri M. Intravitreal bevacizumab with or without triamcinolone for refractory diabetic macular edema: long-term results of a clinical trial. J Ophthalmic Vis Res. 2013;8(2):99-106.

48. Azad R, Sain S, Sharma YR, Mahajan D. Comparison of intravitreal bevacizumab, intravitreal triamcinolone acetonide, and macular grid augmentation in refractory diffuse diabetic macular edema: A prospective, randomized study. Oman J Ophthalmol. 2012;5(3):166-170. doi:10.4103/0974-620x.106100.

49. Chan CK, Lai TY, Mohamed S, et al. Combined high-dose subtenon triamcinolone, intravitreal bevacizumab, and laser photocoagulation for refractory diabetic macular edema: a pilot study. Retina. 2012;32(4):672-678. doi:10.1097/ IAE.0b013e31823043c6.

50. Unsal E, Eltutar K, Sultan P, Erkul SO, Osmanbasoglu OA. Efficacy and safety of intravitreal dexamethasone implants for treatment of refractory diabetic macular edema. Korean J Ophthalmol. 2017;31(2):115-122. doi:10.3341/kjo.2017.31.2.115.

51. Pacella F, Romano MR, Turchetti $\mathrm{P}$, et al. An eighteen-month follow-up study on the effects of intravitreal dexamethasone implant in diabetic macular edema refractory to anti-VEGF therapy. Int J Ophthalmol. 2016;9(10):1427-1432. doi:10.18240/ ijo.2016.10.10.

52. Escobar-Barranco JJ, Pina-Marin B, Fernandez-Bonet $M$. Dexamethasone implants in patients with naive or refractory diffuse diabetic macular edema. Ophthalmologica. 2015;233(34):176-185. doi:10.1159/000371770.

53. Iglicki M, Busch C, Zur D, et al. Dexamethasone implant for diabetic macular edema in naive compared with refractory eyes: The International Retina Group Real-Life 24-Month Multicenter Study. The IRGREL-DEX Study. Retina. 2018. doi:10.1097/ iae.0000000000002196.

54. Maturi RK, Bleau L, Saunders J, Mubasher M, Stewart MW. A 12-month, single-masked, randomized controlled study of eyes with persistent diabetic macular edema after multiple anti-VEGF injections to assess the efficacy of the dexamethasone-delayed delivery system as an adjunct to bevacizumab compared with continued bevacizumab monotherapy. Retina. 2015;35(8):16041614. doi:10.1097/iae.0000000000000533.

55. Maturi RK, Glassman AR, Liu D, et al. Effect of adding dexamethasone to continued ranibizumab treatment in patients with persistent diabetic macular edema: A DRCR network phase 2 randomized clinical trial. JAMA Ophthalmol. 2018;136(1):29-38. doi:10.1001/jamaophthalmol.2017.4914.

56. Busch C, Zur D, Fraser-Bell S, et al. Shall we stay, or shall we switch? Continued anti-VEGF therapy versus early switch to dexamethasone implant in refractory diabetic macular edema. Acta Diabetol. 2018;55(8):789-796. doi:10.1007/s00592-0181151-x.

57. National Institute for Health and Clinical Care Excellence (NICE). Fluocinolone acetonide intravitreal implant for treating chronic diabetic macular edema after an inadequate response to prior therapy. Technology appraisal guidance TA301. London: NICE; 2013.

58. Schmit-Eilenberger VK. A novel intravitreal fluocinolone acetonide implant (lluvien $(\mathbb{R})$ ) in the treatment of patients with chronic diabetic macular edema that is insufficiently responsive to other medical treatment options: a case series. Clin Ophthalmol. 2015;9:801-811. doi:10.2147/opth.s79785.

59. Massin P, Erginay A, Dupas B, Couturier A, Tadayoni R. Efficacy and safety of sustained-delivery fluocinolone acetonide intravitreal implant in patients with chronic diabetic macular 
edema insufficiently responsive to available therapies: a real-life study. Clin Ophthalmol. 2016;10:1257-1264. doi:10.2147/opth. s105385.

60. Elaraoud I, Andreatta W, Kidess A, et al. Use of flucinolone acetonide for patients with diabetic macular oedema: patient selection criteria and early outcomes in real world setting. BMC Ophthalmol. 2016;16:3. doi:10.1186/s12886-015-0178-9.

61. Elaraoud I, Quhill H, Quhill F. Case series investigating the efficacy and safety of bilateral fluocinolone acetonide (ILUVIEN(®)) in patients with diabetic macular edema: 10 eyes with 12 months follow-up. Ophthalmol Ther. 2016;5(1):105-109. doi:10.1007/ s40123-016-0049-3.

62. Chang-Lin JE, Burke JA, Peng Q, et al. Pharmacokinetics of a sustained-release dexamethasone intravitreal implant in vitrectomized and nonvitrectomized eyes. Invest Ophthalmol Vis Sci. 2011;52(7):4605-4609. doi:10.1167/iovs.10-6387.

63. Lee SS, Ghosn C, Yu Z, et al. Vitreous VEGF clearance is increased after vitrectomy. Invest Ophthalmol Vis Sci. 2010;51(4):21352138. doi:10.1167/iovs.09-3582.

64. Boyer DS, Faber D, Gupta S, et al. Dexamethasone intravitreal implant for treatment of diabetic macular edema in vitrectomized patients. Retina. 2011;31(5):915-923. doi:10.1097/ IAE.0b013e318206d18c.
65. Kumar A, Alfahad Q, Mitra A, Elsherbiny S, Lip PL. Intravitreal fluocinolone acetonide (lluvien) for treatment of refractory diabetic macular oedema in vitrectomised eyes. Eye (Lond). 2016;30(5):763-764. doi:10.1038/eye.2015.281.

66. Pessoa B, Coelho J, Correia N, Ferreira N, Beirao M, Meireles A. Fluocinolone acetonide intravitreal implant 190 mug (ILUVIEN(R)) in vitrectomized versus nonvitrectomized eyes for the treatment of chronic diabetic macular edema. Ophthalmic Res. 2018;59(2):6875. doi:10.1159/000484091.

67. Abdel Hadi AM. Evaluation of vitrectomy with planned foveal detachment as surgical treatment for refractory diabetic macular edema with or without vitreomacular interface abnormality. J Ophthalmol. 2018;2018:9246384. doi:10.1155/2018/9246384.

68. Ghassemi F, Bazvand F, Roohipoor R, Yaseri M, Hassanpoor N, Zarei M. Outcomes of vitrectomy, membranectomy and internal limiting membrane peeling in patients with refractory diabetic macular edema and non-tractional epiretinal membrane. J Curr Ophthalmol. 2016;28(4):199-205. doi:10.1016/j. joco.2016.08.006.

69. Amoaku WM, Saker S, Stewart EA. A review of therapies for diabetic macular oedema and rationale for combination therapy. Eye (Lond). 2015;29(9):1115-1130. doi:10.1038/eye.2015.110. 